\title{
The Role of Ubiquitination in Regulation of Innate Immune Signaling
}

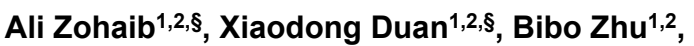 \\ Jing $\mathrm{Ye}^{1,2}$, Shengfeng Wan ${ }^{1,2}$, Huanchun Chen ${ }^{1,2}$, \\ Xueqin $\mathrm{Liu}^{3 *}$, and Shengbo $\mathrm{Cao}^{1,2 *}$ \\ ${ }^{1}$ State Key Laboratory of Agricultural Microbiology, \\ Huazhong Agricultural University, Wuhan, Hubei, 430070, \\ P. R. China \\ ${ }^{2}$ Laboratory of Animal Virology, College of Veterinary \\ Medicine, Huazhong Agricultural University, Wuhan, Hubei, \\ 430070, P. R. China \\ ${ }^{3}$ Department of Aquatic Animal Medicine, College of \\ Fisheries, Huazhong Agricultural University, Wuhan \\ 430070, P. R. China \\ $\S$ These authors contributed equally to this work \\ * Correspondence: xueqinliu@mail.hzau.edu.cn; \\ sbcao@mail.hzau.edu.cn
}

http://dx.doi.org/10.21775/cimb.018.001

Abbreviations: See Table 1.

\begin{abstract}
Ubiquitination, also denoted ubiquitylation, is a posttranslational modification that has been implicated in the regulation of both innate and adaptive immune responses. Ubiquitination plays crucial roles in innate immune signaling by ensuring the proper orchestration of several signaling mediators that constitute a functional immune response. Herein, we briefly summarize the latest discoveries concerning the molecular ubiquitination-related machinery that senses, assembles, and disassembles innate immune signaling mediators.
\end{abstract}

\section{Introduction}

The mammalian immune system, which involves a complex yet tightly regulated network of interactions among different types of cells, cell receptors, and signaling pathways, constantly battles invading pathogens. In addition to the aforementioned immune-system participants, its specificity and complexity also depend on posttranslational modifications of proteins involved in the initiation, maintenance, and termination of immune responses. These posttranslational modifications involve the addition of a chemical group or another protein(s) at one or more site of substrate. To date, more than 200 types of posttranslational modifications have been reported (Kho et al., 2004); with phosphorylation, ubiquitination, and sumoylation being the most extensively studied and well characterized.

Ubiquitination is a key posttranslational modification regulating numerous biological processes at various cellular levels, e.g., protein trafficking, the cell cycle, and immune responses. The addition of ubiquitin to a substrate protein usually involves three main steps: activation by a ubiquitin-activating enzyme (E1), conjugation by a ubiquitin-conjugating enzyme (E2), and ligation by a ubiquitin ligase (E3) (Pickart, 2001). The addition of ubiquitin can affect the substrate protein in one of several ways: it can alter its sub-cellular location, mediate its potential for proteasomal degradation, and/or modify its interaction with another protein. During ubiquitination, a single ubiquitin (mono-ubiquitination) or multiple ubiquitin adducts (polyubiquitination) are being added to lysine residue of a substrate protein (Hershko and Ciechanover, 1998). Each ubiquitin molecule contains seven lysine residues and a free $\mathrm{N}$ terminus (K6, K11, K27, K29, K33, $\mathrm{K} 48$, and $\mathrm{K} 63$ ) thus allowing the formation of diversified ubiquitin linkages via polyubiquitination. In addition, a donor ubiquitin molecule can also attach to a receptor ubiquitin via the amino terminal methionine (M1) resulting in M1 or linear-linkages (Kirisako et al., 2006). These complex and varied structures enable ubiquitination to transmit diverse functional signals that determine the fate of a substrate protein. The well-studied K63-linked chains mediate the functions of various cellular proteins involved in inflammatory signaling complexes, whereas K48-linked chains predominantly facilitate the proteasomal-mediated degradation of substrates (Hershko and Ciechanover, 1998; Chen and Sun, 2009). To date, other types of ubiquitin linkages have not been well studied and are usually referred to as atypical ubiquitinations. The functions so far attributed to atypical linkages are very diverse but also suggest roles in inflammation, the immune system, and/or the cell cycle (Morris and Solomon, 2004; Boname et al., 2010; Gerlach et al., 2011; Wickliffe et al., 2011).

E3s generally determine substrate specificity and have been divided into three subfamilies based on their domain structure: HECT, RING domain or RBR ligases. E3s containing the RING domain directly transfer ubiquitin to a target protein, whereas E3s containing the HECT domain facilitate the transfer of E2-loaded ubiquitin to the substrate (Pickart, 2001; Rotin and Kumar, 2009). Recently, it has been shown that RBR ligases possess features of both RING and HECT E3s (Wenzel et al., 2011; Smit et al., 2012). DUBs can reverse ubiquitination. Several DUBs have been identified that fine tune the specific ubiquitination process and regulate diverse signaling pathways. Generally, DUBs are classified as one of five types depending upon their protease domain, i.e., ubiquitinspecific protease (USP), ovarian tumor protease (OTU), Machado-Joseph-disease protease (Josephins), ubiquitin C-terminal hydrolase, or JAB1/MPN/Mov34 metalloenzyme (Nijman et al., 2005; Komander et al., 2009a; Reyes-Turcu et al., 2009). DUBs are also categorized into three subclasses defined by their functional attribute, i.e., DUBs that cleave ubiquitin precursors, DUBs that rescue proteins from ubiquitin-mediated degradation and reverse the related biological process(es) by removing ubiquitin chains from the substrate, and DUBs that edit ubiquitin chains to 
Table 1. Glossary

\begin{tabular}{|c|c|}
\hline ABIN1 & A20 binding inhibitor of NF-KB 1 \\
\hline ClAP & Cellular inhibitor of apoptosis protein \\
\hline DUBs & Deubiquitinating enzymes \\
\hline FADD & Fas-associated protein with death domain \\
\hline HECT & Homology to E6AP C-terminus \\
\hline HOIL-1 & Heme-oxidized iron-responsive element-binding protein 2 ubiquitin ligase-1 \\
\hline HOIP & HOIL-1-interacting protein \\
\hline IKK & Inhibitor of $\mathrm{KB}$ kinase \\
\hline IRAK & IL1-R-associated kinase \\
\hline LGP2 & Laboratory of genetics and physiology gene 2 \\
\hline LUBAC & Linear ubiquitin chain assembly complex \\
\hline MAPK & Mitogen-activated protein kinase \\
\hline MAVS & Mitochondrial antiviral signaling protein \\
\hline MDA5 & Melanoma differentiation-associated gene 5 \\
\hline MyD88 & Myeloid differentiation primary response gene 88 \\
\hline MEF & Mouse embryonic fibroblast \\
\hline NEMO & NF-KB kinase B essential modulator \\
\hline OTULIN & OTU DUB with linear linkage specificity \\
\hline RING & Really Interesting New Gene \\
\hline RBR & RING-between-RING \\
\hline RNF & RING-finger protein \\
\hline RIP & Receptor interacting protein \\
\hline SHARPIN & $\begin{array}{l}\text { SH3 and multiple ankyrin repeat domain protein (SHANK)-associated RBCK1 homology } \\
\text { (RH)-domain interacting Protein }\end{array}$ \\
\hline TAB & TAK1-binding protein \\
\hline TAK & Transforming growth factor- $\beta$ activated kinase 1 \\
\hline TNF & Tumor necrosis factor \\
\hline TNFR1 & TNF receptor 1 \\
\hline TRADD & TNFR1-associated death-domain (DD) \\
\hline TRAF & TNF receptor-associated factor \\
\hline TRIF & TIR-domain-containing adaptor protein inducing interferon- $\beta$-mediated transcription-factor \\
\hline TRIM25 & Tripartite motif containing protein 25 \\
\hline TAX1BP1 & Human T-cell leukemia virus type I (Tax1) binding protein 1 \\
\hline USP & Ubiquitin-specific protease \\
\hline XIAP & X-linked inhibitor of apoptosis protein \\
\hline
\end{tabular}

modify signaling pathways (Komander et al., 2009a; Reyes-Turcu et al., 2009). Although some evidence suggests important roles for DUBs in immune response regulation, including the negative regulation of NF-kB signaling by CYLD, a USP DUB, and A20, an OTU DUB (Trompouki et al., 2003; Wertz et al., 2004), the target substrates and physiological functions of most DUBs have yet to be identified.

In short, ubiquitination is mediated by hundreds of E3, several E2s, and DUBs that dictate specificity of deubiquitinating molecule. In the following sections we summarize what is known about the integral roles of ubiquitination in host innate-immune defense mechanisms.

\section{Ubiquitination mediates innate immune responses}

Germ-line pattern-recognition receptors (PRRs) recognize pathogen-associated molecular patterns and initiate the host immune response against invading pathogens. This family of receptors includes membrane-bound toll-like receptors (TLRs) and cytosolic receptors, e.g., nucleotidebinding oligomerization domain (NOD)-like receptors (NLRs) and retinoic acid-inducible gene I (RIG-I)-like 
helicases or RIG-I-like receptors (RLRs). PRR activation results in the activation of the NF-KB and MAPK signaling pathways leading to the production of proinflammatory cytokines, chemokines, and interferons (IFNs). These inflammatory mediators initiate an immune response and begin the recruitment of immune cells to the site of infection.

Over the last decade, many studies have partially characterized the diversified roles of ubiquitination in immune system regulation. Although ubiquitination is an integral part of inflammatory signaling, its role(s) in cell death still needs to be more fully explored. Below, we summarize our current understanding of how ubiquitination and deubiquitination control diverse innate immune responses.

\section{TLR signaling}

TLRs are membrane-bound PRRs that sense a broad array of pathogens and have been divided into two main groups: expressed in the plasma membrane (TLR1, 2, 4, 5, 6, and
10) or located in the endosome (TLR3, 7, 8, and 9). TLR activation leads to the recruitment of several downstream signaling mediators and ultimately results in the production of pro-inflammatory cytokines and/or type I IFNs (Takeda et al., 2003). TLR signaling can also induce cell death (Feoktistova et al., 2011; Kaiser et al., 2013). MyD88dependent signaling, engaged by TLR4 recruits IRAK1 and IRAK4 that subsequently interact with TRAF3, TRAF6 (a molecule shared by several signaling pathways), and clAPs (Figure 1) (Tseng et al., 2010). In this cascade, TRAF6 interacts with a multi-molecular E2 complex denoted Ubc13/Uev1A, resulting in the ubiquitinosome (Deng et al., 2000). Subsequently, within this TLR4 signaling complex (TLR4-SC) TRAF6 is self-conjugated to K63-linkages and also ubiquitinates clAP1/2, which then recruits TAB-TAK and IKK-NEMO, resulting in NF-KB and MAPK signaling (Kanayama et al., 2004; Wu et al., 2006; Vallabhapurapu and Karin, 2009). Interestingly, detachment of TLR4-SC from the plasma membrane and translocation to the cytosol, which is required for the activation of the

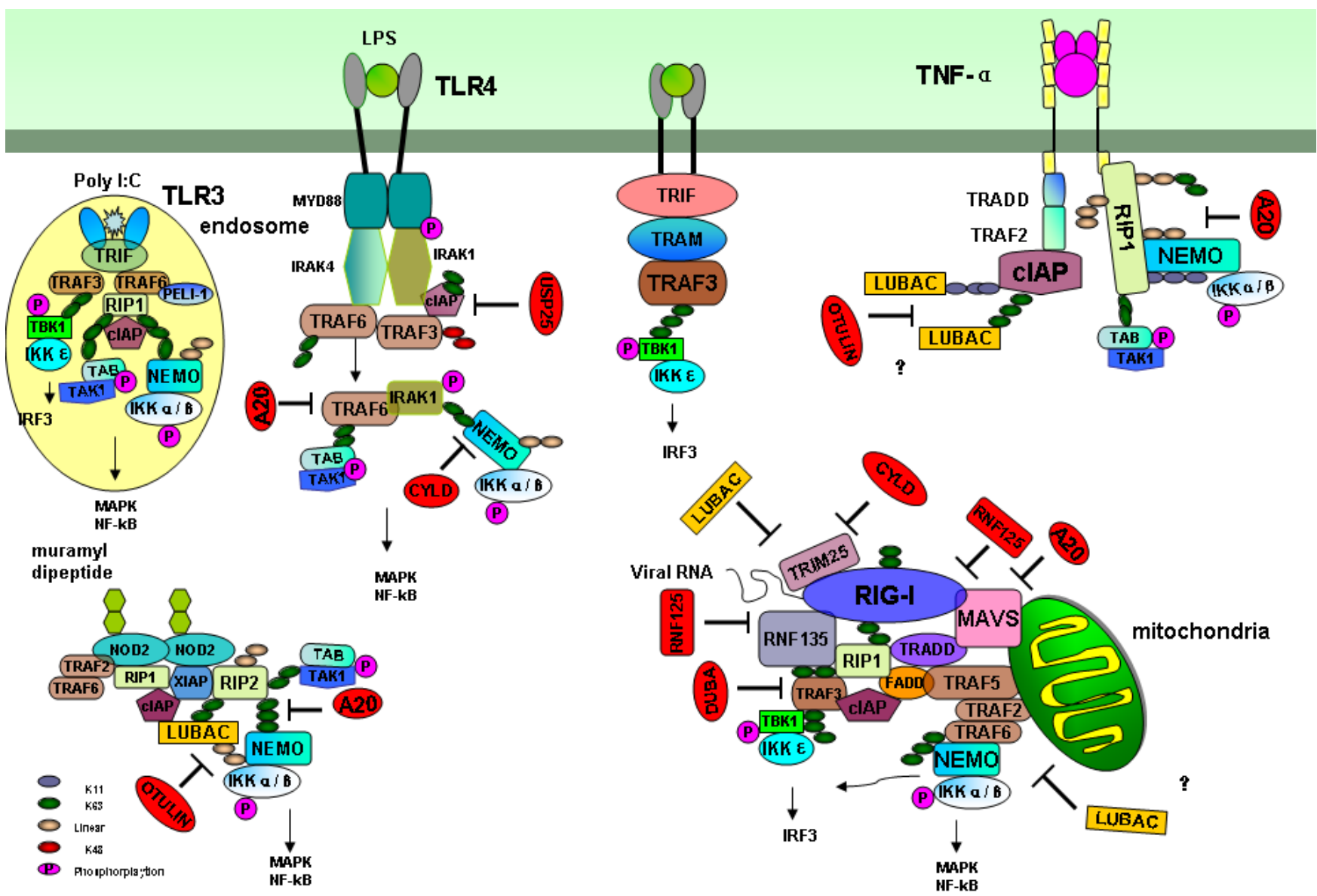

Figure 1. Ubiquitination is involved in PRR signaling. Several E3s are required for TLR3, TLR4, NOD2, RIG-1, and TNFR signaling. In TLR3-mediated signaling, TRIF, TRAF3, and TRAF6 are recruited. TRAF3 recruitment results in IRF3 activation and subsequent production of IFN. TRAF6 is required for NF-kB kinase B activation. TRAF3 and TRAF6 also regulate the TLR4 signaling pathway. RIG-I signaling is regulated by TRIM25 and TRAF6, which promote the recruitment of NEMO and the IKK complex. In the NOD2 signaling complex, XIAP and LUBAC promote ubiquitination of RIP2, thus allowing the activation of the NF-KB kinase B signaling pathway. In TNFR-mediated signaling, cIAPs, RIP1, and LUBAC play important roles in activating subsequent inflammatory pathways. 
TAB-TAK complex, is facilitated by clAP1/2 K48-mediated ubiquitination of TRAF3 (Matsuzawa et al., 2008; Tseng et al., 2010). Upon TLR3 and TLR4 activation, TRIF is also recruited, which then binds to RIP1 and TRAF6. Both TRAF6 and RIP1 are subsequently polyubiquitinated, and activates NF-KB and/or type-I IFNs, depending upon the E3s recruited to the TLR-SC (Chang et al., 2009; Vallabhapurapu and Karin, 2009) (Figure 1). Despite the key role of K63-linked ubiquitin chains in TLR signaling, the requirements for and recruitment patterns of the major E2s and $E 3 s$ to facilitate K63-linked ubiquitination remain elusive. In response to IL-1 $\beta$ or LPS, TRAF6 is thought to interact with the E2 Ubc13/Uev1A to facilitate K63-linked polyubiquitination of IRAK1 and TAK1 (Wang et al., 2001; Conze et al., 2008; Windheim et al., 2008). Genetic analysis has provided conflicting results on the role of Ubc13 in TLR4 signaling. Deletion of Ubc13 in bone marrow-derived macrophages, MEFs, and $B$ cells does not impair TRAF6-mediated NF-KB activation in the IL-1R/ TLR4 signaling complex (Yamamoto et al., 2006). Conversely, macrophages and splenocytes derived from Ubc13+/- mice show reduced NF-KB activation following LPS stimulation (Fukushima et al., 2007). Furthermore, the exact role of the RING domain in TRAF6 during IL-1R/ TLR4 signaling is not clear, although TRAF6-deficient cells have significantly reduced NF-KB activation following LPS or IL-1 $\beta$ stimulation (Lomaga et al., 1999). Introduction of a TRAF6 mutant lacking the RING domain into TRAF6deficient cells rescues the effect of TRAF6 deficiency on NF-KB activation in the IL-1R/TLR4 signaling complex (Kobayashi et al., 2001), whereas a RING-domain point mutant of TRAF6 fails to restore NF-KB activation in TRAF6-deficient cells (Lamothe et al., 2007). Therefore, more genetic and biochemical studies are needed to probe the precise mechanism of Ubc13-TRAF6-mediated regulation of NF-KB activation in IL-1R/TLR4 signaling.

Several other common E3s play important roles in TLR signaling. PELI-1 regulates TRIF-dependent TLR signaling (Chang et al., 2009), and clAPs regulates cell death and inflammation (Feoktistova et al., 2011; Estornes et al., 2012). Recently, the LUBAC complex (consisting of the E3 ligases HOIL-1L and HOIP, and the accessory protein SHARPIN) has been suggested to regulate TLR signaling (Ikeda et al., 2011; Sasaki et al., 2013). LUBAC catalyzes the linear polyubiquitination of NEMO upon activation by IL-1R/TLR agonists, leading to IKK activation (Tokunaga et al., 2009). Although it is not clear whether there is functional redundancy between K63-linked ubiquitination and linear ubiquitination, a recent study by Emmerich et al. (2013) suggests that linear and K63-linked ubiquitin chains work together to modify the functions of signaling molecules such as MyD88 and IRAK4 in IL-1R/TLR4 signaling (Emmerich et al., 2013). There is some uncertainty regarding how IKK activation is positively regulated by linear ubiquitination as mediated by LUBAC, because SHARPIN-deficient macrophages exhibit no reduction in IKK activation following TLR stimulation (Zak et al., 2011). Recent biochemical studies also revealed another type of ubiquitin chain-mediated regulation of IKK activation. Unanchored K63-linked polyubiquitin chains (which are not conjugated to a protein) are polymerized by the TRAF6-Ubc13 complex, which subsequently activates
TAK1 through the binding of TAB2 (Xia et al., 2009). Further studies are needed to determine the functional in vivo significance of unanchored ubiquitin chains in IL-1R/ TLR signaling pathways.

To tightly regulate immune-response activation, DUBs act as important ubiquitination-regulating agents (Figure 1). Recently, USP25 was described as an off switch for TLR4mediated MAPK signaling. Interestingly, USP25 only limits the production of pro-inflammatory cytokines by interacting with MyD88 and stabilizing TRAF3, resulting in a balance between TLR-triggered cytokines and type-I IFNs (Zhong et al., 2013). Another important DUB, USP7, stabilizes NF-kB by preventing its proteasomal degradation in response to diverse TLR signaling cascades (Colleran et al., 2013). In addition, another study suggests that USP7 has DUB activity for TRAF6 in the TLR pathway (Daubeuf et al., 2009). A20, a member of a multi-protein complex that includes Itch, RNF11, TAX1BP1, and ABIN1/2/3, can neutralize the TRAF6 ubiquitinosome by targeting polyubiquitinated TRAF6 (Lin et al., 2008). Macrophages deficient in A20 show prolonged TRAF6 ubiquitination following LPS stimulation (Boone et al., 2004). A recent study has revealed that $A 20$ inhibits IL-1 $\beta$-induced interactions of TRAF6 with Ubc13 or $\mathrm{UbcH} 5$, which triggers their proteasomal degradation (Shembade et al., 2010a). Recent evidence suggests that CYLD is also a TLRmodulating DUB, as it negatively regulates NF-KB activation of TLR4 signaling (Sun, 2010).

\section{RLR and NLR signaling}

RLRs and NLRs are cytosolic PPRs. Three types of RLRs exist, namely RIG-I, MDA5, and LGP2. Upon sensing viral particles, RIG-I becomes K63 ubiquitinated by RNF135 and TRIM25 and by free K63-linked chains, which results in binding of RIG-I to the adaptor protein MAVS (Takeuchi and Akira, 2010; Jiang et al., 2012). Upon activation, MAVSrecruited TRADD further recruits multiple downstream mediators to trigger antiviral responses (Liu et al., 2013). The recruitment of the TRAF3 results in the activation of IRF3, which leads to production of IFN (Michallet et al., 2008). Conversely, TRAF6 recruitment, in conjunction with the adaptor molecules TRAF2 and TRAF5, results in activation of NF-kB and IRF3 (Liu et al., 2013). In addition, TRADD recruits RIP1, caspase-8, and FADD, which are required for IRF3 and NF-KB activation (Takahashi et al., 2006; Michallet et al., 2008). Interestingly, RIP1 ubiquitination is involved in maximal activation of the RIG-I mediated antiviral response and its subsequent termination. Although RIP1 ubiquitination acts as a positive regulator of RIG-I signaling, it is also required for its cleavage by caspase- 8 in the RIG-I signaling complex, resulting in down regulation of RIG-I-mediated IFN production (Rajput et al., 2011). The types of ubiquitination linkages involved in this dual function of RIP1 still need to be determined.

Other E3 ligases, e.g., LUBAC, RNF125, and CIAP1/2, also mediate RIG-I signaling cascades. cIAP1/2 facilitates activation of IRF3 and NF-KB by mediating K63 polyubiquitination of TRAF3 and TRAF6 (Mao et al., 2010). In contrast, RNF125 and LUBAC negatively regulate RIG-Imediated immune responses (Figure 1). RNF125 attaches K48-linked chains to RIG-I and MAVS, targeting them for 
proteasomal degradation (Arimoto et al., 2007), whereas LUBAC disrupts the TRIM25-RIG-I interaction directly or by ubiquitin-mediated proteasomal degradation of TRIM25 (Inn et al., 2011). In line with these observations, infection with Sendai virus induces K-48 and linear polyubiquitination of TRIM25, whereas HOIP-knockdown cells show increased IFN production following infection (Inn et al., 2011). Further, LUBAC can also linearly ubiquitinate NEMO and then negatively regulate the RIG-I-mediated immune responses (Belgnaoui et al., 2012). Accordingly, vesicular stomatitis virus replication was decreased due to increased IFN production in SHARPIN-deficient MEFs (Belgnaoui et al., 2012). It has, therefore, been proposed that linear ubiquitination has an opposing role in the context of the RIG-I-mediated antiviral response compared with other signaling pathways, e.g., those triggered by TLR (Sasaki et al., 2013), IL-1 (Emmerich et al., 2013), TNF (Haas et al., 2009; Gerlach et al., 2011), and NOD2 (Damgaard et al., 2012; Fiil et al., 2013). The detailed mechanisms of linear ubiquitination-mediated RIG-I signaling require further investigation to be fully understood.

RIG-I-mediated immune responses are also regulated by several DUBs, including CYLD, which deubiquitinates RIG-I (Zhang et al., 2008) thereby inhibiting its signaling. In response to Sendei virus infection, enhanced IFN production has been observed following CYLD knockdown, whereas CYLD ectopic expression inhibits this enhancement (Friedman et al., 2008). Moreover, bone marrow-derived cells and fibroblasts derived from CYLDdeficient mice show constitutive activation of TBK1 (Zhang et al., 2008). Another DUB, DUBA, also modulates RIG-Imediated immune signaling by deubiquitinating TRAF3. Overexpression of DUBA has been shown to disrupt the TRAF3-TBK1 interaction (Kayagaki et al., 2007). Recently, A20 was reported to counteract RIG-I-mediated IRF3 and NF-KB responses, but if A20 directly interacts with RIG-I and/or MAVS still needs to be determined (Lin et al., 2006; Harhaj and Dixit, 2012). Furthermore, Itch, a member of the A20 complex has been reported to attach K-48-linked polyubiquitination chains to MAVS (You et al., 2009), but, similarly, its direct interaction with MAVS has not been reported.

NLR signaling also relies on ubiquitination-regulated mechanisms. Two of the most well studied NLRs are NOD1 and NOD2. Stimulation of NLRs results in a robust immune response via production of cytokines, chemokines, and IFNs. The NOD complex includes RIP2, which is ubiquitinated by clAPs (Bertrand et al., 2009). Specifically, cIAP1 and 2 induce K63-linked ubiquitination of RIP2 (Bertrand et al., 2009). Moreover, E3 ligases, e.g., TRAF2, 5 , and 6 , are also recruited to the NOD signaling complex, where they function as adaptor molecules and also crosstalk with components of other signaling pathways, e.g., those involving TLRs and RLRs (Figure 1). XIAP is also recruited to the NOD signaling complex and directly binds to RIP2. Furthermore, XIAP mediates recruitment of LUBAC, which adds linear ubiquitin chains to RIP2 (Damgaard et al., 2012; Fiil et al., 2013). This results in the activation of TAB-TAK and IKK-NEMO complexes and subsequent activation of the NF-KB and MAPK signaling pathways. The importance of XIAP in the innate immune response has been shown using several intracellular bacterial infection models (Lopez and Meier, 2010). XIAPdeficient mice suffer from increased pulmonary infectivity and are unable to clear bacteria following Chlamydophila pneumoniae infection (Prakash et al., 2010). Similarly, XIAP-deficient mice exhibit decreased survival following Listeria monocytogenes intraperitoneal injection (Bauler et al., 2008).

A20 negatively regulates NLR signaling by deubiquitinating RIP2 (Hitotsumatsu et al., 2008). In the absence of A20, increased RIP2 ubiquitination and prolonged NF-KB activation are observed both in vitro and in vivo (Hitotsumatsu et al., 2008). Recent studies have also identified the DUB OTULIN as negatively regulating NOD2 signaling by limiting linear ubiquitination of LUBAC (Figure 1; (Fiil et al., 2013). Overexpression of OTULIN results in inhibition of LUBAC and to a lesser extent XIAPmediated NF-KB activation, whereas OTULIN knockdown results in over-activation of NF-KB following stimulation by the NOD2 ligand MDP (Fiil et al., 2013).

The crucial role of ubiquitination in NLRP3-mediated immune responses has also been demonstrated (Dempsey, 2013). Although clAPs are implicated in the regulation of inflammasome activation, two opposing views exist regarding the role of clAPs in the NLRP3 signaling complex. One report suggests that clAPs directly mediate K63-polyubiquitination of caspases-1-containing complexes, thus positively regulating their activation (Labbé et al., 2011). In contrast, clAPs and XIAP have been reported to negatively regulate the NLRP3-mediated inflammasome (Vince et al., 2012). Recently, the positively regulating DUB BRCC3 was identified which directly deubiquitinates NLRP3 and stabilizes the NLRP3inflammasome. Knockdown of BRCC3 results in increased NLRP3 ubiquitination. The DUB activity of BRCC3 is also required for caspase-1 activation and IL-1 processing (Py et al., 2013).

Taken together, these studies provide new insights into the importance of ubiquitination in NLR signaling. To comprehensively understand NLR signaling and the inflammasome, further studies are needed to determine the precise role of other E3s and DUBs.

\section{TNF signaling}

Activation of the TNF signaling pathway can result in two opposing outcomes. On the one hand, this signaling cascade results in inflammation and cellular protection, and, on the other hand, it results in the activation of the cellular apoptosis-signaling cascade (Micheau and Tschopp, 2003). TNF- $\alpha$, a major immune effector, binds to TNFR1 to trigger activation of the NF-KB and MAPK pathways in an ubiquitin-dependent manner (Zinngrebe et al., 2014). Initial recruitment of TRADD and TRAF2, or alternately TRAF5, allows the subsequent recruitment of clAPs and RIP1 (Figure 1). These clAPs along with TRAF2/5 facilitate K63-linked ubiquitination of RIP1, resulting in the assembly of downstream mediators and activation of the NF-KB and MAPK pathways (Figure 1; (Wu et al., 2006; Ea et al., 2006; Bertrand et al., 2008; Varfolomeev et al., 2008). TNF- $\alpha$-induced ubiquitination of RIP1 is not observed in TRAF2-deficient MEFs, but it remains unclear whether TRAF2 directly catalyzes the 
polyubiquitination of RIP1 (Lee et al., 2004). clAP1 and cIAP2 are also RING domain-containing E3s reported to catalyze RIP1 polyubiquitination (Mahoney et al., 2008), but a recent study also suggests that CIAP1, along with UbcH5, generates K11-linked polyubiquitin chains on RIP1 in the TNFR1 signaling complex to activate NF-KB in a nondegradative manner (Dynek et al., 2010). Although several studies clearly demonstrate the pivotal roles of clAP1/2 in RIP1 polyubiquitination (Mahoney et al., 2008; Varfolomeev et al., 2008), the detailed mechanisms underlying clAP1/2 and TRAF2/5 interplay remain elusive.

The interaction between polyubiquitinated RIP1 and TAB2/3 facilitates the recruitment of TAK1 to TNFR1, which aids in the activation of IKK (Kanayama et al., 2004). Although it is clear that TAK 1 activates IKK by phosphorylation (Blonska et al., 2005), it is still unclear whether TAK1 phosphorylates IKK directly or through a mediator. Mutation of K377 in RIP1, a key residue for its ubiquitination, prevents the downstream recruitment of the IKK complex to TNFR1 and results in inactivation of IKK (Ea et al., 2006).

Ubc13/Uev1A is an E2 that specifically catalyzes addition of K63-linked ubiquitin chains. Although the crucial role of Ubc13/Uev1A in NF-KB activation by TNF- $\alpha$ has been described (Deng et al., 2000), several other studies have reported a very limited role for Ubc13 in TNF-amediated NF-KB activation. For example, MEFs deficient in Ubc13 show no effect on MAPK activation by TNF stimulation (Yamamoto et al., 2006). Furthermore, human cells expressing an endogenous $\mathrm{K} 63$ mutant exhibit no effect on IKK activation by TNF- $\alpha$ (Xu et al., 2009). Moreover, they showed that Ubc5, but not Ubc13, is required for IKK activation by TNF- $\alpha$ (Xu et al., 2009). These results suggest that either polyubiquitin chains or other E2s and E3s are involved in the TNF- $\alpha$-mediated NF$\mathrm{KB}$ signaling pathway.

Recently, the central role of LUBAC in TNFR1mediated NF-KB activation was determined (Tokunaga et al., 2009; Haas et al., 2009; Iwai, 2012). LUBAC regulates IKK activation in TNF signaling complex. Deletion and overexpression studies revealed that the LUBAC catalyzes the addition of linear polyubiquitination chains to NEMO, resulting in NF-kB activation (Gerlach et al., 2011; Haas et al., 2009). This linear ubiquitination facilitates the recruitment of the IKK complex, which appears to be similar to RIP1-mediated IKK activation by K63-linked polyubiquitin chains (Gerlach et al., 2011; Tokunaga et al., 2011). Although K63 and linear ubiquitination exhibit equivalent open conformations, these two chains are recognized by distinct components of the NF-kB signaling pathway (Komander et al., 2009b). Further studies are needed to determine the precise roles of the LUBAC in the TNF signaling pathway.

DUBs play important roles in NF-KB signaling pathways by regulating the effects of ubiquitination. The two well-studied DUBs A20 and CYLD negatively regulate TNF-mediated NF-KB and MAPK activation (Kovalenko et al., 2003; Wertz et al., 2004; Jono et al., 2004). A20 acts as a dual-function ubiquitin-editing enzyme (Wertz et al., 2004). K63-linked polyubiquitin chains are first removed by the OTU DUB domain of A20, and then A20 conjugates K48-linked polyubiquitination to RIPI through its C-terminal
E3 domain to facilitate its proteasome-mediated degradation (Wertz et al., 2004). A20-deficient mice exhibit prolonged NF-KB responses and develop severe multiorgan inflammation (Lee et al., 2000). A20, in conjunction with TAXBP1, Itch, and RNF11, assembles a complex that attenuates TNFR1 signaling (Shembade et al., 2007, 2008, 2009, 2010b). Recent studies also suggest that $A 20$ can inhibit LUBAC-mediated NF-KB responses in a DUBindependent manner (Tokunaga et al., 2012; Verhelst et al., 2012). The DUB CYLD is also known to inhibit NF-kB signaling. CYLD possesses a USP-type DUB domain that acts on linear and K63-linkages (Brummelkamp et al., 2003; Kovalenko et al., 2003; Trompouki et al., 2003). The DUB OTULIN (also named gumby) is the most recently characterized member of the OTU family of DUBs. OTULIN exclusively recognizes linear ubiquitin chains and inhibits TNF- $\alpha$-induced NF-KB responses by preventing NEMORIP1 association (Fiil et al., 2013; Keusekotten et al., 2013). Several other DUBs, e.g., USP31 (Tzimas et al., 2006), USP21 (Xu et al., 2010), Cezanne (Enesa et al., 2008), USP11 (Sun et al., 2010; Yamaguchi et al., 2007), and USP4 (Zhou et al., 2012), have also been shown to regulate TNF- $\alpha$ signaling by terminating NF-KB activation. Further genetic and biochemical studies are required to determine the exact roles of these DUBs in the TNF- $\alpha$ induced NF-KB signaling pathway.

\section{Summary}

The mammalian immune system possesses remarkable abilities to precisely modulate defense mechanisms against invading pathogens, sensing when, where, and for how long defenses are needed. The immune system works in a highly sophisticated manner, although we do not fully understand its molecular interactions and functionalities. Herein, by summarizing some of the available evidences, we propose that ubiquitination and deubiquitination play pivotal roles in regulating immune responses. Ubiquitination and deubiquitination of key proteins within signaling cascades tightly regulate the complex mechanisms of immune signaling. Defects in the ubiquitin pathway can greatly alter the immune response, resulting in increased pathogenicity of invading pathogens. Although recent findings have improved our understanding of the various ubiquitination pathways, we still lack a complete understanding of the exact roles of this modification. There is a great need to elucidate the precise roles of individual ubiquitinating/deubiquitinating molecules in regulating host immune responses and also to determine how invading pathogens exploit the host ubiquitin system for their own good. Detailed investigations of these modifications may also reveal novel therapeutic options for several diseases.

\section{Acknowledgments}

This work was supported by grants from the National Natural Sciences Foundation of China (31172325, 31472221), the Special Fund for Agro-Scientific Research in the Public Interest (201203082), and the Fundamental Research Funds for the Central Universities (2011PY002, 2013PY051). 


\section{References}

Arimoto, K., Takahashi, H., Hishiki, T., Konishi, H., Fujita, T., and Shimotohno, K. (2007). Negative regulation of the RIG-I signaling by the ubiquitin ligase RNF125. Proc. Natl. Acad. Sci. U. S. A. 104, 7500-7505.

Bauler, L.D., Duckett, C.S., and O'Riordan, M.X.D. (2008). XIAP regulates cytosol-specific innate immunity to Listeria infection. PLoS Pathog. 4, e1000142.

Belgnaoui, S.M., Paz, S., Samuel, S., Goulet, M.-L., Sun, Q., Kikkert, M., Iwai, K., Dikic, I., Hiscott, J., and Lin, R. (2012). Linear ubiquitination of NEMO negatively regulates the interferon antiviral response through disruption of the MAVS-TRAF3 complex. Cell Host Microbe 12, 211-222.

Bertrand, M.J.M., Milutinovic, S., Dickson, K.M., Ho, W.C., Boudreault, A., Durkin, J., Gillard, J.W., Jaquith, J.B., Morris, S.J., and Barker, P.A. (2008). clAP1 and clAP2 facilitate cancer cell survival by functioning as E3 ligases that promote RIP1 ubiquitination. Mol. Cell 30, 689-700.

Bertrand, M.J.M., Doiron, K., Labbé, K., Korneluk, R.G., Barker, P.A., and Saleh, M. (2009). Cellular inhibitors of apoptosis clAP1 and ClAP2 are required for innate immunity signaling by the pattern recognition receptors NOD1 and NOD2. Immunity 30, 789-801.

Blonska, M., Shambharkar, P.B., Kobayashi, M., Zhang, D., Sakurai, H., Su, B., and Lin, X. (2005). TAK1 is recruited to the tumor necrosis factor-alpha (TNF-alpha) receptor 1 complex in a receptor-interacting protein (RIP)dependent manner and cooperates with MEKK3 leading to NF-kappaB activation. J. Biol. Chem. 280, 4305643063.

Boname, J.M., Thomas, M., Stagg, H.R., Xu, P., Peng, J., and Lehner, P.J. (2010). Efficient internalization of MHC I requires lysine-11 and lysine-63 mixed linkage polyubiquitin chains. Traffic Cph. Den. 11, 210-220.

Boone, D.L., Turer, E.E., Lee, E.G., Ahmad, R.-C., Wheeler, M.T., Tsui, C., Hurley, P., Chien, M., Chai, S., Hitotsumatsu, O., et al. (2004). The ubiquitin-modifying enzyme $A 20$ is required for termination of Toll-like receptor responses. Nat. Immunol. 5, 1052-1060.

Brummelkamp, T.R., Nijman, S.M.B., Dirac, A.M.G., and Bernards, R. (2003). Loss of the cylindromatosis tumour suppressor inhibits apoptosis by activating NF-kappaB. Nature 424, 797-801.

Chang, M., Jin, W., and Sun, S.-C. (2009). Peli1 facilitates TRIF-dependent Toll-like receptor signaling and proinflammatory cytokine production. Nat. Immunol. 10, 1089-1095.

Chen, Z.J., and Sun, L.J. (2009). Nonproteolytic functions of ubiquitin in cell signaling. Mol. Cell 33, 275-286.

Colleran, A., Collins, P.E., O'Carroll, C., Ahmed, A., Mao, X., McManus, B., Kiely, P.A., Burstein, E., and Carmody, R.J. (2013). Deubiquitination of NF-kB by UbiquitinSpecific Protease-7 promotes transcription. Proc. Natl. Acad. Sci. U. S. A. 110, 618-623.

Conze, D.B., Wu, C.-J., Thomas, J.A., Landstrom, A., and Ashwell, J.D. (2008). Lys63-linked polyubiquitination of IRAK-1 is required for interleukin-1 receptor- and toll-like receptor-mediated NF-kappaB activation. Mol. Cell. Biol. 28, 3538-3547.

Damgaard, R.B., Nachbur, U., Yabal, M., Wong, W.W.-L., Fiil, B.K., Kastirr, M., Rieser, E., Rickard, J.A.,
Bankovacki, A., Peschel, C., et al. (2012). The ubiquitin ligase XIAP recruits LUBAC for NOD2 signaling in inflammation and innate immunity. Mol. Cell 46, 746-758.

Daubeuf, S., Singh, D., Tan, Y., Liu, H., Federoff, H.J., Bowers, W.J., and Tolba, K. (2009). HSV ICP0 recruits USP7 to modulate TLR-mediated innate response. Blood 113, 3264-3275.

Dempsey, L.A. (2013). NLRP3 ubiquitination. Nat. Immunol. 14, 118-118.

Deng, L., Wang, C., Spencer, E., Yang, L., Braun, A., You, J., Slaughter, C., Pickart, C., and Chen, Z.J. (2000). Activation of the IkappaB kinase complex by TRAF6 requires a dimeric ubiquitin-conjugating enzyme complex and a unique polyubiquitin chain. Cell 103, 351-361.

Dynek, J.N., Goncharov, T., Dueber, E.C., Fedorova, A.V., Izrael-Tomasevic, A., Phu, L., Helgason, E., Fairbrother, W.J., Deshayes, K., Kirkpatrick, D.S., et al. (2010). cIAP1 and UbcH5 promote K11-linked polyubiquitination of RIP1 in TNF signalling. EMBO J. 29, 4198-4209.

Ea, C.-K., Deng, L., Xia, Z.-P., Pineda, G., and Chen, Z.J. (2006). Activation of IKK by TNFalpha requires sitespecific ubiquitination of RIP1 and polyubiquitin binding by NEMO. Mol. Cell 22, 245-257.

Emmerich, C.H., Ordureau, A., Strickson, S., Arthur, J.S.C., Pedrioli, P.G.A., Komander, D., and Cohen, P. (2013). Activation of the canonical IKK complex by K63/M1linked hybrid ubiquitin chains. Proc. Natl. Acad. Sci. U. S. A. 110, 15247-15252.

Enesa, K., Zakkar, M., Chaudhury, H., Luong, L.A., Rawlinson, L., Mason, J.C., Haskard, D.O., Dean, J.L.E., and Evans, P.C. (2008). NF-kappaB suppression by the deubiquitinating enzyme Cezanne: a novel negative feedback loop in pro-inflammatory signaling. J. Biol. Chem. 283, 7036-7045.

Estornes, Y., Toscano, F., Virard, F., Jacquemin, G., Pierrot, A., Vanbervliet, B., Bonnin, M., Lalaoui, N., MercierGouy, P., Pachéco, Y., et al. (2012). dsRNA induces apoptosis through an atypical death complex associating TLR3 to caspase-8. Cell Death Differ. 19, 1482-1494.

Feoktistova, M., Geserick, P., Kellert, B., Dimitrova, D.P., Langlais, C., Hupe, M., Cain, K., MacFarlane, M., Häcker, G., and Leverkus, M. (2011). clAPs block Ripoptosome formation, a RIP1/caspase-8 containing intracellular cell death complex differentially regulated by cFLIP isoforms. Mol. Cell 43, 449-463.

Fiil, B.K., Damgaard, R.B., Wagner, S.A., Keusekotten, K., Fritsch, M., Bekker-Jensen, S., Mailand, N., Choudhary, C., Komander, D., and Gyrd-Hansen, M. (2013). OTULIN restricts Met1-linked ubiquitination to control innate immune signaling. Mol. Cell 50, 818-830.

Friedman, C.S., O'Donnell, M.A., Legarda-Addison, D., Ng, A., Cárdenas, W.B., Yount, J.S., Moran, T.M., Basler, C.F., Komuro, A., Horvath, C.M., et al. (2008). The tumour suppressor CYLD is a negative regulator of RIGI-mediated antiviral response. EMBO Rep. 9, 930-936.

Fukushima, T., Matsuzawa, S., Kress, C.L., Bruey, J.M., Krajewska, M., Lefebvre, S., Zapata, J.M., Ronai, Z., and Reed, J.C. (2007). Ubiquitin-conjugating enzyme Ubc13 is a critical component of TNF receptor-associated factor (TRAF)-mediated inflammatory responses. Proc. Natl. Acad. Sci. U. S. A. 104, 6371-6376. 
Gerlach, B., Cordier, S.M., Schmukle, A.C., Emmerich, C.H., Rieser, E., Haas, T.L., Webb, A.I., Rickard, J.A., Anderton, H., Wong, W.W.-L., et al. (2011). Linear ubiquitination prevents inflammation and regulates immune signalling. Nature 471, 591-596.

Haas, T.L., Emmerich, C.H., Gerlach, B., Schmukle, A.C., Cordier, S.M., Rieser, E., Feltham, R., Vince, J., Warnken, U., Wenger, T., et al. (2009). Recruitment of the linear ubiquitin chain assembly complex stabilizes the TNF-R1 signaling complex and is required for TNFmediated gene induction. Mol. Cell 36, 831-844.

Harhaj, E.W., and Dixit, V.M. (2012). Regulation of NF-kB by deubiquitinases. Immunol. Rev. 246, 107-124.

Hershko, A., and Ciechanover, A. (1998). The ubiquitin system. Annu. Rev. Biochem. 67, 425-479.

Hitotsumatsu, O., Ahmad, R.-C., Tavares, R., Wang, M., Philpott, D., Turer, E.E., Lee, B.L., Shiffin, N., Advincula, R., Malynn, B.A., et al. (2008). The ubiquitin-editing enzyme A20 restricts nucleotide-binding oligomerization domain containing 2-triggered signals. Immunity 28, 381-390.

Ikeda, F., Deribe, Y.L., Skånland, S.S., Stieglitz, B., Grabbe, C., Franz-Wachtel, M., van Wijk, S.J.L., Goswami, P., Nagy, V., Terzic, J., et al. (2011). SHARPIN forms a linear ubiquitin ligase complex regulating NF-KB activity and apoptosis. Nature 471, 637-641.

Inn, K.-S., Gack, M.U., Tokunaga, F., Shi, M., Wong, L.-Y., Iwai, K., and Jung, J.U. (2011). Linear ubiquitin assembly complex negatively regulates RIG-I- and TRIM25mediated type I interferon induction. Mol. Cell 41, 354365.

Iwai, K. (2012). Diverse ubiquitin signaling in NF-KB activation. Trends Cell Biol. 22, 355-364.

Jiang, X., Kinch, L.N., Brautigam, C.A., Chen, X., Du, F., Grishin, N.V., and Chen, Z.J. (2012). Ubiquitin-induced oligomerization of the RNA sensors RIG-I and MDA5 activates antiviral innate immune response. Immunity 36 , 959-973.

Jono, H., Lim, J.H., Chen, L.-F., Xu, H., Trompouki, E., Pan, Z.K., Mosialos, G., and Li, J.-D. (2004). NF-kappaB is essential for induction of CYLD, the negative regulator of NF-kappaB: evidence for a novel inducible autoregulatory feedback pathway. J. Biol. Chem. 279, 36171-36174.

Kaiser, W.J., Sridharan, H., Huang, C., Mandal, P., Upton, J.W., Gough, P.J., Sehon, C.A., Marquis, R.W., Bertin, J., and Mocarski, E.S. (2013). Toll-like receptor 3-mediated necrosis via TRIF, RIP3, and MLKL. J. Biol. Chem. 288, 31268-31279.

Kanayama, A., Seth, R.B., Sun, L., Ea, C.-K., Hong, M., Shaito, A., Chiu, Y.-H., Deng, L., and Chen, Z.J. (2004). TAB2 and TAB3 activate the NF-kappaB pathway through binding to polyubiquitin chains. Mol. Cell 15, 535-548.

Kayagaki, N., Phung, Q., Chan, S., Chaudhari, R., Quan, C., O'Rourke, K.M., Eby, M., Pietras, E., Cheng, G., Bazan, J.F., et al. (2007). DUBA: a deubiquitinase that regulates type I interferon production. Science 318, 1628-1632.

Keusekotten, K., Elliott, P.R., Glockner, L., Fiil, B.K., Damgaard, R.B., Kulathu, Y., Wauer, T., Hospenthal, M.K., Gyrd-Hansen, M., Krappmann, D., et al. (2013).
OTULIN antagonizes LUBAC signaling by specifically hydrolyzing Met1-linked polyubiquitin. Cell 153, 13121326.

Kho, Y., Kim, S.C., Jiang, C., Barma, D., Kwon, S.W., Cheng, J., Jaunbergs, J., Weinbaum, C., Tamanoi, F., Falck, J., et al. (2004). A tagging-via-substrate technology for detection and proteomics of farnesylated proteins. Proc. Natl. Acad. Sci. U. S. A. 101, 1247912484.

Kirisako, T., Kamei, K., Murata, S., Kato, M., Fukumoto, H., Kanie, M., Sano, S., Tokunaga, F., Tanaka, K., and Iwai, K. (2006). A ubiquitin ligase complex assembles linear polyubiquitin chains. EMBO J. 25, 4877-4887.

Kobayashi, N., Kadono, Y., Naito, A., Matsumoto, K., Yamamoto, T., Tanaka, S., and Inoue, J. (2001). Segregation of TRAF6-mediated signaling pathways clarifies its role in osteoclastogenesis. EMBO J. 20, 1271-1280.

Komander, D., Clague, M.J., and Urbé, S. (2009a). Breaking the chains: structure and function of the deubiquitinases. Nat. Rev. Mol. Cell Biol. 10, 550-563.

Komander, D., Reyes-Turcu, F., Licchesi, J.D.F., Odenwaelder, P., Wilkinson, K.D., and Barford, D. (2009b). Molecular discrimination of structurally equivalent Lys 63-linked and linear polyubiquitin chains. EMBO Rep. 10, 466-473.

Kovalenko, A., Chable-Bessia, C., Cantarella, G., Israël, A., Wallach, D., and Courtois, G. (2003). The tumour suppressor CYLD negatively regulates NF-kappaB signalling by deubiquitination. Nature 424, 801-805.

Labbé, K., Mclntire, C.R., Doiron, K., Leblanc, P.M., and Saleh, M. (2011). Cellular inhibitors of apoptosis proteins clAP1 and clAP2 are required for efficient caspase-1 activation by the inflammasome. Immunity 35, 897-907.

Lamothe, B., Besse, A., Campos, A.D., Webster, W.K., Wu, H., and Darnay, B.G. (2007). Site-specific Lys-63-linked tumor necrosis factor receptor-associated factor 6 autoubiquitination is a critical determinant of I kappa B kinase activation. J. Biol. Chem. 282, 4102-4112.

Lee, E.G., Boone, D.L., Chai, S., Libby, S.L., Chien, M., Lodolce, J.P., and Ma, A. (2000). Failure to regulate TNFinduced NF-kappaB and cell death responses in A20deficient mice. Science 289, 2350-2354.

Lee, T.H., Shank, J., Cusson, N., and Kelliher, M.A. (2004). The Kinase Activity of Rip1 Is Not Required for Tumor Necrosis Factor- $\alpha$-induced IkB Kinase or p38 MAP Kinase Activation or for the Ubiquitination of Rip1 by Traf2. J. Biol. Chem. 279, 33185-33191.

Lin, R., Yang, L., Nakhaei, P., Sun, Q., Sharif-Askari, E., Julkunen, I., and Hiscott, J. (2006). Negative regulation of the retinoic acid-inducible gene l-induced antiviral state by the ubiquitin-editing protein A20. J. Biol. Chem. 281, 2095-2103.

Lin, S.-C., Chung, J.Y., Lamothe, B., Rajashankar, K., Lu, M., Lo, Y.-C., Lam, A.Y., Darnay, B.G., and Wu, H. (2008). Molecular basis for the unique deubiquitinating activity of the NF-kappaB inhibitor A20. J. Mol. Biol. 376, 526-540.

Liu, S., Chen, J., Cai, X., Wu, J., Chen, X., Wu, Y.-T., Sun, L., and Chen, Z.J. (2013). MAVS recruits multiple ubiquitin E3 ligases to activate antiviral signaling cascades. eLife 2, e00785. 
Lomaga, M.A., Yeh, W.C., Sarosi, I., Duncan, G.S., Furlonger, C., Ho, A., Morony, S., Capparelli, C., Van, G., Kaufman, S., et al. (1999). TRAF6 deficiency results in osteopetrosis and defective interleukin-1, CD40, and LPS signaling. Genes Dev. 13, 1015-1024.

Lopez, J., and Meier, P. (2010). To fight or die - inhibitor of apoptosis proteins at the crossroad of innate immunity and death. Curr. Opin. Cell Biol. 22, 872-881.

Mahoney, D.J., Cheung, H.H., Mrad, R.L., Plenchette, S., Simard, C., Enwere, E., Arora, V., Mak, T.W., Lacasse, E.C., Waring, J., et al. (2008). Both clAP1 and clAP2 regulate TNFalpha-mediated NF-kappaB activation. Proc. Natl. Acad. Sci. U. S. A. 105, 11778-11783.

Mao, A.-P., Li, S., Zhong, B., Li, Y., Yan, J., Li, Q., Teng, C., and Shu, H.-B. (2010). Virus-triggered ubiquitination of TRAF3/6 by clAP1/2 is essential for induction of interferon-beta (IFN-beta) and cellular antiviral response. J. Biol. Chem. 285, 9470-9476.

Matsuzawa, A., Tseng, P.-H., Vallabhapurapu, S., Luo, J.L., Zhang, W., Wang, H., Vignali, D.A.A., Gallagher, E., and Karin, M. (2008). Essential cytoplasmic translocation of a cytokine receptor-assembled signaling complex. Science 321, 663-668.

Michallet, M.-C., Meylan, E., Ermolaeva, M.A., Vazquez, J., Rebsamen, M., Curran, J., Poeck, H., Bscheider, M., Hartmann, G., König, M., et al. (2008). TRADD protein is an essential component of the RIG-like helicase antiviral pathway. Immunity 28, 651-661.

Micheau, O., and Tschopp, J. (2003). Induction of TNF receptor I-mediated apoptosis via two sequential signaling complexes. Cell 114, 181-190.

Morris, J.R., and Solomon, E. (2004). BRCA1 : BARD1 induces the formation of conjugated ubiquitin structures, dependent on $\mathrm{K} 6$ of ubiquitin, in cells during DNA replication and repair. Hum. Mol. Genet. 13, 807-817.

Nijman, S.M.B., Luna-Vargas, M.P.A., Velds, A., Brummelkamp, T.R., Dirac, A.M.G., Sixma, T.K., and Bernards, R. (2005). A Genomic and Functional Inventory of Deubiquitinating Enzymes. Cell 123, 773786.

Pickart, C.M. (2001). Mechanisms underlying ubiquitination. Annu. Rev. Biochem. 70, 503-533.

Prakash, H., Albrecht, M., Becker, D., Kuhlmann, T., and Rudel, T. (2010). Deficiency of XIAP leads to sensitization for Chlamydophila pneumoniae pulmonary infection and dysregulation of innate immune response in mice. J. Biol. Chem. 285, 20291-20302.

Py, B.F., Kim, M.-S., Vakifahmetoglu-Norberg, H., and Yuan, J. (2013). Deubiquitination of NLRP3 by BRCC3 critically regulates inflammasome activity. Mol. Cell 49, 331-338.

Rajput, A., Kovalenko, A., Bogdanov, K., Yang, S.-H., Kang, T.-B., Kim, J.-C., Du, J., and Wallach, D. (2011). RIG-I RNA helicase activation of IRF3 transcription factor is negatively regulated by caspase-8-mediated cleavage of the RIP1 protein. Immunity 34, 340-351.

Reyes-Turcu, F.E., Ventii, K.H., and Wilkinson, K.D. (2009). Regulation and cellular roles of ubiquitin-specific deubiquitinating enzymes. Annu. Rev. Biochem. 78, 363397.
Rotin, D., and Kumar, S. (2009). Physiological functions of the HECT family of ubiquitin ligases. Nat. Rev. Mol. Cell Biol. 10, 398-409.

Sasaki, Y., Sano, S., Nakahara, M., Murata, S., Kometani, K., Aiba, Y., Sakamoto, S., Watanabe, Y., Tanaka, K., Kurosaki, T., et al. (2013). Defective immune responses in mice lacking LUBAC-mediated linear ubiquitination in B cells. EMBO J. 32, 2463-2476.

Shembade, N., Harhaj, N.S., Liebl, D.J., and Harhaj, E.W. (2007). Essential role for TAX1BP1 in the termination of TNF-alpha-, IL-1- and LPS-mediated NF-kappaB and JNK signaling. EMBO J. 26, 3910-3922.

Shembade, N., Harhaj, N.S., Parvatiyar, K., Copeland, N.G., Jenkins, N.A., Matesic, L.E., and Harhaj, E.W. (2008). The E3 ligase Itch negatively regulates inflammatory signaling pathways by controlling the function of the ubiquitin-editing enzyme A20. Nat. Immunol. 9, 254-262.

Shembade, N., Parvatiyar, K., Harhaj, N.S., and Harhaj, E.W. (2009). The ubiquitin-editing enzyme $A 20$ requires RNF11 to downregulate NF-kappaB signalling. EMBO J. 28, 513-522.

Shembade, N., Ma, A., and Harhaj, E.W. (2010a). Inhibition of NF-KB Signaling by A20 Through Disruption of Ubiquitin Enzyme Complexes. Science 327, 1135-1139.

Shembade, N., Ma, A., and Harhaj, E.W. (2010b). Inhibition of NF-kappaB signaling by $\mathrm{A} 20$ through disruption of ubiquitin enzyme complexes. Science 327, 1135-1139.

Smit, J.J., Monteferrario, D., Noordermeer, S.M., van Dijk, W.J., van der Reijden, B.A., and Sixma, T.K. (2012). The E3 ligase HOIP specifies linear ubiquitin chain assembly through its RING-IBR-RING domain and the unique LDD extension. EMBO J. 31, 3833-3844.

Sun, S.-C. (2010). CYLD: a tumor suppressor deubiquitinase regulating NF-kappaB activation and diverse biological processes. Cell Death Differ. 17, 25-34.

Sun, W., Tan, X., Shi, Y., Xu, G., Mao, R., Gu, X., Fan, Y., Yu, Y., Burlingame, S., Zhang, H., et al. (2010). USP11 negatively regulates TNFalpha-induced NF-kappaB activation by targeting on IkappaBalpha. Cell. Signal. 22, 386-394.

Takahashi, K., Kawai, T., Kumar, H., Sato, S., Yonehara, S., and Akira, S. (2006). Cutting Edge: Roles of Caspase-8 and Caspase-10 in Innate Immune Responses to Double-Stranded RNA. J. Immunol. 176, 4520-4524.

Takeda, K., Kaisho, T., and Akira, S. (2003). Toll-Like Receptors. Annu. Rev. Immunol. 21, 335-376.

Takeuchi, O., and Akira, S. (2010). Pattern recognition receptors and inflammation. Cell 140, 805-820.

Tokunaga, F., Sakata, S., Saeki, Y., Satomi, Y., Kirisako, T., Kamei, K., Nakagawa, T., Kato, M., Murata, S., Yamaoka, S., et al. (2009). Involvement of linear polyubiquitylation of NEMO in NF-kappaB activation. Nat. Cell Biol. 11, 123-132.

Tokunaga, F., Nakagawa, T., Nakahara, M., Saeki, Y., Taniguchi, M., Sakata, S., Tanaka, K., Nakano, H., and Iwai, K. (2011). SHARPIN is a component of the NF-KBactivating linear ubiquitin chain assembly complex. Nature 471, 633-636.

Tokunaga, F., Nishimasu, H., Ishitani, R., Goto, E., Noguchi, T., Mio, K., Kamei, K., Ma, A., Iwai, K., and Nureki, O. (2012). Specific recognition of linear 
polyubiquitin by $A 20$ zinc finger 7 is involved in NF-kB regulation. EMBO J. 31, 3856-3870.

Trompouki, E., Hatzivassiliou, E., Tsichritzis, T., Farmer, H., Ashworth, A., and Mosialos, G. (2003). CYLD is a deubiquitinating enzyme that negatively regulates NFkappaB activation by TNFR family members. Nature 424 , 793-796.

Tseng, P.-H., Matsuzawa, A., Zhang, W., Mino, T., Vignali, D.A.A., and Karin, M. (2010). Different modes of ubiquitination of the adaptor TRAF3 selectively activate the expression of type I interferons and proinflammatory cytokines. Nat. Immunol. 11, 70-75.

Tzimas, C., Michailidou, G., Arsenakis, M., Kieff, E., Mosialos, G., and Hatzivassiliou, E.G. (2006). Human ubiquitin specific protease 31 is a deubiquitinating enzyme implicated in activation of nuclear factor-kappaB. Cell. Signal. 18, 83-92.

Vallabhapurapu, S., and Karin, M. (2009). Regulation and Function of NF-KB Transcription Factors in the Immune System. Annu. Rev. Immunol. 27, 693-733.

Varfolomeev, E., Goncharov, T., Fedorova, A.V., Dynek, J.N., Zobel, K., Deshayes, K., Fairbrother, W.J., and Vucic, D. (2008). C-IAP1 and C-IAP2 are critical mediators of tumor necrosis factor alpha (TNFalpha)induced NF-kappaB activation. J. Biol. Chem. 283, 24295-24299.

Verhelst, K., Carpentier, I., Kreike, M., Meloni, L., Verstrepen, L., Kensche, T., Dikic, I., and Beyaert, R. (2012). A20 inhibits LUBAC-mediated NF-KB activation by binding linear polyubiquitin chains via its zinc finger 7 . EMBO J. 31, 3845-3855.

Vince, J.E., Wong, W.W.-L., Gentle, I., Lawlor, K.E., Allam, R., O'Reilly, L., Mason, K., Gross, O., Ma, S., Guarda, G., et al. (2012). Inhibitor of apoptosis proteins limit RIP3 kinase-dependent interleukin-1 activation. Immunity 36, 215-227.

Wang, C., Deng, L., Hong, M., Akkaraju, G.R., Inoue, J., and Chen, Z.J. (2001). TAK1 is a ubiquitin-dependent kinase of MKK and IKK. Nature 412, 346-351.

Wenzel, D.M., Lissounov, A., Brzovic, P.S., and Klevit, R.E. (2011). UBCH7 reactivity profile reveals parkin and HHARI to be RING/HECT hybrids. Nature 474, 105-108.

Wertz, I.E., O'Rourke, K.M., Zhou, H., Eby, M., Aravind, L., Seshagiri, S., Wu, P., Wiesmann, C., Baker, R., Boone, D.L., et al. (2004). De-ubiquitination and ubiquitin ligase domains of A20 downregulate NF-kappaB signalling. Nature 430, 694-699.

Wickliffe, K.E., Williamson, A., Meyer, H.-J., Kelly, A., and Rape, M. (2011). K11-linked ubiquitin chains as novel regulators of cell division. Trends Cell Biol. 21, 656-663.

Windheim, M., Stafford, M., Peggie, M., and Cohen, P. (2008). Interleukin-1 (IL-1) induces the Lys63-linked polyubiquitination of IL-1 receptor-associated kinase 1 to facilitate NEMO binding and the activation of IkappaBalpha kinase. Mol. Cell. Biol. 28, 1783-1791.

Wu, C.-J., Conze, D.B., Li, T., Srinivasula, S.M., and Ashwell, J.D. (2006). Sensing of Lys 63-linked polyubiquitination by NEMO is a key event in NF-kappaB activation [corrected]. Nat. Cell Biol. 8, 398-406.

Xia, Z.-P., Sun, L., Chen, X., Pineda, G., Jiang, X., Adhikari, A., Zeng, W., and Chen, Z.J. (2009). Direct Activation of Protein Kinases by Unanchored Polyubiquitin Chains. Nature 461, 114-119.

Xu, G., Tan, X., Wang, H., Sun, W., Shi, Y., Burlingame, S., Gu, X., Cao, G., Zhang, T., Qin, J., et al. (2010). Ubiquitin-specific peptidase 21 inhibits tumor necrosis factor alpha-induced nuclear factor kappaB activation via binding to and deubiquitinating receptor-interacting protein 1. J. Biol. Chem. 285, 969-978.

Xu, M., Skaug, B., Zeng, W., and Chen, Z.J. (2009). A ubiquitin replacement strategy in human cells reveals distinct mechanisms of IKK activation by TNFalpha and IL-1beta. Mol. Cell 36, 302-314.

Yamaguchi, T., Kimura, J., Miki, Y., and Yoshida, K. (2007). The deubiquitinating enzyme USP11 controls an IkappaB kinase alpha (IKKalpha)-p53 signaling pathway in response to tumor necrosis factor alpha (TNFalpha). J. Biol. Chem. 282, 33943-33948.

Yamamoto, M., Okamoto, T., Takeda, K., Sato, S., Sanjo, H., Uematsu, S., Saitoh, T., Yamamoto, N., Sakurai, H., Ishii, K.J., et al. (2006). Key function for the Ubc13 E2 ubiquitin-conjugating enzyme in immune receptor signaling. Nat. Immunol. 7, 962-970.

You, F., Sun, H., Zhou, X., Sun, W., Liang, S., Zhai, Z., and Jiang, Z. (2009). PCBP2 mediates degradation of the adaptor MAVS via the HECT ubiquitin ligase AIP4. Nat. Immunol. 10, 1300-1308.

Zak, D.E., Schmitz, F., Gold, E.S., Diercks, A.H., Peschon, J.J., Valvo, J.S., Niemistö, A., Podolsky, I., Fallen, S.G., Suen, R., et al. (2011). Systems analysis identifies an essential role for SHANK-associated RH domaininteracting protein (SHARPIN) in macrophage Toll-like receptor 2 (TLR2) responses. Proc. Natl. Acad. Sci. U. S. A. $108,11536-11541$.

Zhang, M., Wu, X., Lee, A.J., Jin, W., Chang, M., Wright, A., Imaizumi, T., and Sun, S.-C. (2008). Regulation of IkappaB kinase-related kinases and antiviral responses by tumor suppressor CYLD. J. Biol. Chem. 283, 1862118626.

Zhong, B., Liu, X., Wang, X., Liu, X., Li, H., Darnay, B.G., Lin, X., Sun, S.-C., and Dong, C. (2013). Ubiquitinspecific protease 25 regulates TLR4-dependent innate immune responses through deubiquitination of the adaptor protein TRAF3. Sci. Signal. 6, ra35.

Zhou, F., Zhang, X., van Dam, H., Ten Dijke, P., Huang, H., and Zhang, L. (2012). Ubiquitin-specific protease 4 mitigates Toll-like/interleukin-1 receptor signaling and regulates innate immune activation. J. Biol. Chem. 287, 11002-11010.

Zinngrebe, J., Montinaro, A., Peltzer, N., and Walczak, H. (2014). Ubiquitin in the immune system. EMBO Rep. 15, 28-45. 


\section{Microbiology / Molecular Biology}

Caister Academic Press is a leading academic publisher of advanced texts in microbiology, molecular biology and medical research. Full details of all our publications at caister.com

- Cyanobacteria: Omics and Manipulation Edited by: DA Los (2017) www.caister.com/cyano3

- Brain-eating Amoebae: Biology and Pathogenesis of Naegleria fowleri

Author: R Siddiqui, IKM Ali, JR Cope, et al. (2016)

"explains the current knowledge and research" (ProtoView) www.caister.com/naegleria

- Foot and Mouth Disease Virus: Current Research and Emerging Trends

Edited by: F Sobrino, E Domingo (2017)

www.caister.com/fmdv

- Staphylococcus: Genetics and Physiology

Edited by: GA Somerville (2016)

www.caister.com/staph2

- Chloroplasts: Current Research and Future Trends Edited by: H Kirchhoff (2016)

www.caister.com/chloroplasts

- Microbial Biodegradation: From Omics to Function and Application

Edited by: J Długoński (2016)

www.caister.com/biodegradation

- Influenza: Current Research

Edited by: Q Wang, YJ Tao (2016)

www.caister.com/flu3

- MALDI-TOF Mass Spectrometry in Microbiology Edited by: M Kostrzewa, S Schubert (2016)

www.caister.com/malditof

- Aspergillus and Penicillium in the Post-genomic Era Edited by: RP Vries, IB Gelber, MR Andersen (2016)

"new and well-presented book" (IMA Fungus)

www.caister.com/aspergillus2

- The Bacteriocins: Current Knowledge and Future

Prospects

Edited by: RL Dorit, SM Roy, MA Riley (2016)

www.caister.com/bacteriocins

- Omics in Plant Disease Resistance

Edited by: V Bhadauria (2016)

"essential reading ... highly recommended" (Biotechnol. Agron.

Soc. Environ.)

www.caister.com/opdr

- Acidophiles: Life in Extremely Acidic Environments

Edited by: R Quatrini, DB Johnson (2016)

"Contributors from a wide range of biological and environmental sciences" (ProtoView)

www.caister.com/acidophiles
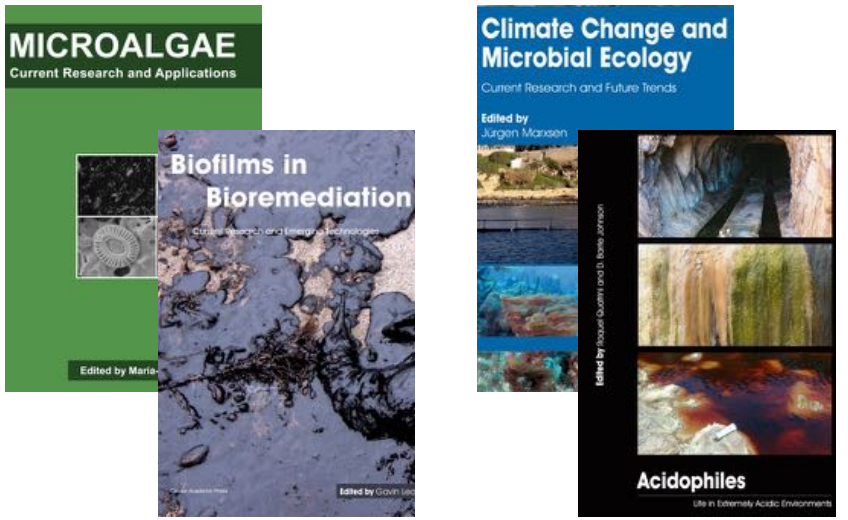
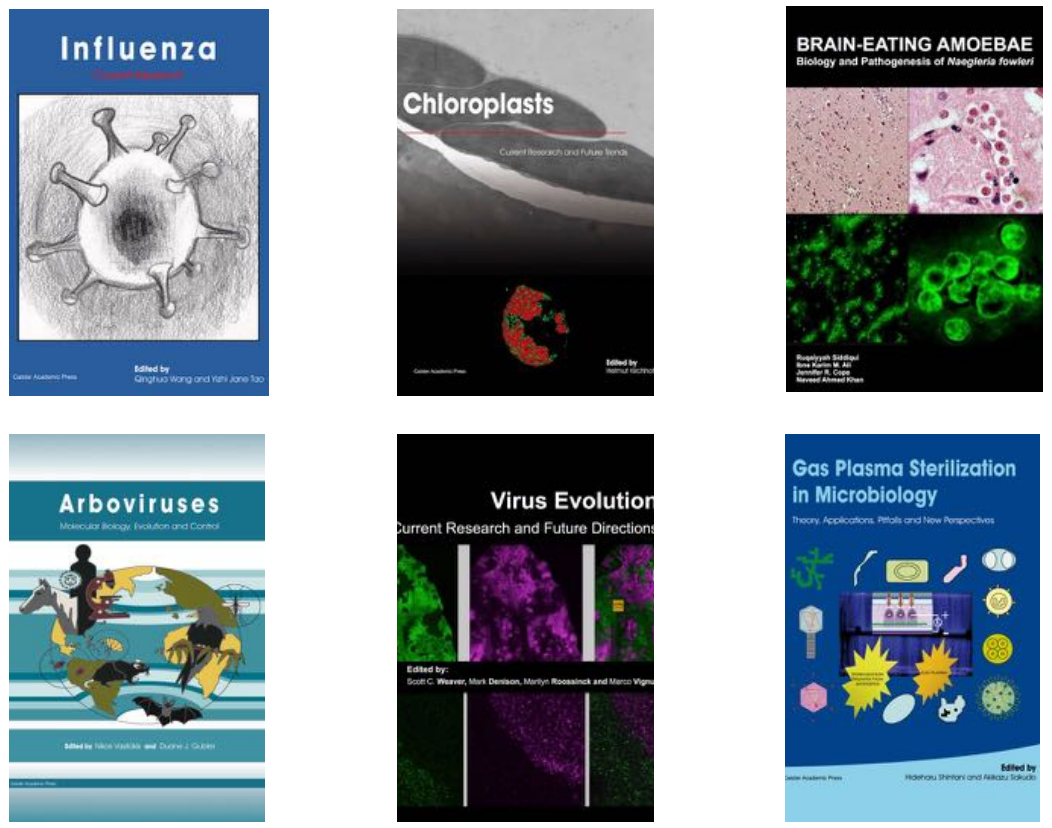

- Climate Change and Microbial Ecology: Current Research and Future Trends

Edited by: J Marxsen (2016)

"impressive" (ASM: Small Things Considered); "written at a high scientific level" (BioSpektrum)

www.caister.com/climate

- Biofilms in Bioremediation: Current Research and Emerging Technologies

Edited by: G Lear (2016)

"describes explicitly the role of biofilms in bioremediation" (Biospektrum); indispensable ... recommended (Biotechnol. Agron. Soc. Environ.) www.caister.com/biorem

- Microalgae: Current Research and Applications

Edited by: MN Tsaloglou (2016)

www.caister.com/microalgae

- Gas Plasma Sterilization in Microbiology: Theory, Applications, Pitfalls and New Perspectives

Edited by: H Shintani, A Sakudo (2016)

"a nice state of the art compilation" (Doodys)

www.caister.com/gasplasma

- Virus Evolution: Current Research and Future Directions Edited by: SC Weaver, M Denison, M Roossinck, et al. (2016) "highly informative ... a pleasure to read" (Microbiol. Today) www.caister.com/virusevol

- Arboviruses: Molecular Biology, Evolution and Control Edited by: N Vasilakis, DJ Gubler (2016)

"a thorough and compelling review ... an outstanding book ... highly recommended" (Am. J. Trop. Med. Hyg.) www.caister.com/arbo

- Shigella: Molecular and Cellular Biology

Edited by: WD Picking, WL Picking (2016)

www.caister.com/shigella

- Aquatic Biofilms: Ecology, Water Quality and Wastewater Treatment

Edited by: AM Romaní, H Guasch, MD Balaguer (2016)

"essential reference book" (Biotechnol. Agron. Soc. Environ.)

www.caister.com/aquaticbiofilms

- Alphaviruses: Current Biology

Edited by: S Mahalingam, L Herrero, B Herring (2016)

"up-to-date review of the field" (Aus. Vet. J.)

www.caister.com/alpha 